\title{
Alcohol-Related Deaths and Hospitalizations by Race, Gender, and Age in California
}

\author{
Mandy Stahre", and Michele Simon ${ }^{2}$ \\ ${ }^{I}$ Division of Epidemiology, School of Public Health, University of Minnesota, USA \\ ${ }^{2}$ Marin Institute, San Rafael, CA, USA
}

\begin{abstract}
Introduction: Excessive alcohol use is the third leading preventable cause of death in the United States each year and responsible for about 10,000 deaths in California alone. In addition, excessive alcohol use is responsible for many hospitalizations due to injuries and illnesses. Alcohol consumption is known to differ by age, sex, and race/ethnicity and these consumption patterns can lead to differences in alcohol-related outcomes.

Methods: Using data from a variety of sources, alcohol-attributable deaths and nonfatal hospitalizations for illnesses and injuries were calculated for California for the year 2006.

Results: Excessive alcohol use resulted in over 10,000 deaths and 72,000 nonfatal hospitalizations in California. The majority of consequences (51\%) were due to chronic illnesses associated with long-term excessive use of alcohol. Overall, males reported more deaths and nonfatal hospitalizations due to excessive alcohol use than women. Alcohol-attributable deaths and hospitalizations are more likely to occur among individuals aged 50-64 years for illnesses and individuals aged 20-34 years for injuries. Older individuals suffered from more chronic conditions such as alcoholic liver disease, while younger individuals were more likely to suffer from injuries, the most common being motor-vehicle traffic crashes. Significant differences in the rate of deaths and nonfatal hospitalizations by race/ethnicity were more common due to injuries and violence than chronic diseases.

Conclusions: This study highlighted key findings of demographic differences in consequences suffered by excessive alcohol use in California. Continued efforts to better evaluate the contribution of alcohol to morbidity and mortality by demographic factors, especially by race and ethnicity, is warranted to prevent and reduce the harm associated with this behavior.
\end{abstract}

\section{INTRODUCTION}

Excessive alcohol use is the third leading preventable cause of death in the United States each year, accounting for approximately 79,000 deaths annually resulting in approximately 2.4 million Years of Potential Life Lost $[1,2]$. Approximately $10 \%$ of these deaths occurred in the state of California alone [3]. Excessive alcohol use is defined as both heavy daily drinking (i.e., consuming more than two drinks per day on average for men and more than 1 drink per day on average for women) and binge drinking (i.e., consuming 5 or more drinks on occasion for men and 4 or more drinks on occasion for women) $[4,5]$. While deaths due to long-term heavy alcohol use usually result from the development of chronic conditions, about half of all alcohol-attributable deaths are associated with episodes of binge drinking resulting in injury deaths [1]. In addition to deaths, alcohol is associated with many injuries and acts of violence. Estimates of the economic costs associated with alcohol use in the United States are close to $\$ 150$ billion annually (in 1998 dollars) [6]. A study by Rosen, Miller and Simon [7] estimated the resulting economic cost for California to be between $\$ 35$ and $\$ 42$ billion annually.

*Address correspondence to this author at the Division of Epidemiology, School of Public Health, University of Minnesota, USA; Tel: 612-625-2022; E-mail: stahre@umn.edu
Alcohol consumption is known to differ by age, sex, and race/ethnicity. Research has shown higher levels of alcohol use among males, whites and younger individuals $[8,9]$. Overall differences in consumption patterns can lead to differences in consequences associated with alcohol use. Men, who on average drink more than women, are three times more likely to die from alcohol-attributable motorvehicle traffic crashes, homicide and suicide than women [1]. However, research has shown that rates of alcoholattributable cancers of the esophagus and larynx have been found to be higher among African American men vs white men $[10,11]$. For California specifically, Sutocky et al. [10] found that black men had a higher age-adjusted death rate associated with alcohol use than all other race/sex groups. However, these results were based upon data from over 20 years ago and it is unclear if these differences still persist. Given the high percentage of overall alcohol-attributable deaths in the US that occurs in California, having more detailed information regarding the groups most effected by harms associated with excessive alcohol use can help to target prevention efforts and reduce the burden of disease. The current report estimates alcohol-attributable deaths and nonfatal hospitalizations for various demographic groups for California. 


\section{MATERIALS AND METHODOLOGY}

\section{Alcohol-Attributable Fatal Illnesses and Injuries Data}

\section{Sources}

To capture the number of fatalities due to illnesses and injuries, we used data from the 2006 California Death Statistical Master File from California Vital Statistics. The Alcohol Related Disease Impact (ARDI) software developed by the Centers for Disease Control and Prevention was used to estimate the proportion of fatal illnesses and injuries that were attributable to alcohol [3] (Table 1). Several attributable fractions were modified specifically to California using information obtained from the Behavioral Risk Factor Surveillance System (BRFSS) on the prevalence of different alcohol use levels for 2006 [12]. These estimates were then applied to relative risk information for certain chronic conditions to calculate alcohol-attributable fractions [13]. The specific methods used by ARDI to calculate alcoholattributable deaths are described in detail elsewhere [1, 7]. Certain conditions that are included in ARDI were not included in the analysis for California. Conditions were not included if there were less than five deaths (or hospitalizations) for that condition; examples include alcoholic gastritis (one death), fetal alcohol syndrome (no deaths or hospitalizations), portal hypertension (three deaths), etc. The specific ICD-10 codes related to the conditions used in ARDI are available on the website [3].

For fatal injury deaths, alcohol-attributable fractions were based on estimates from a study of emergency department visits by Smith and colleagues [14]. The exception is motor-vehicle traffic crashes. Currently, the ARDI system uses data from the Fatality Analysis Reporting System (FARS) administered by the National Highway Traffic Safety Administration (NHTSA) to produce alcohol-attributable fractions for motor-vehicle traffic crashes [15]. The FARS system allows for age, race, and sex-specific alcohol-attributable fractions for motor-vehicle traffic crashes. National estimates for alcohol-attributable fractions were used for race and ethnicity due to validity concerns of underreporting or misinformation of race and ethnicity at the state-level. However, for age and sex, alcoholattributable fractions were generated specific to California crash information. All alcohol-attributable fractions for motor-vehicle traffic crashes were estimated for the year 2006.

\section{Race/Ethnicity}

Information on race and ethnicity of decedents was provided in the 2006 California Death Statistical Master File. Several steps had to be utilized to determine the appropriate race and ethnicity for each decedent due to varying methods used by counties in California to identify race and ethnicity. Race was collapsed into the minimum racial categories established in the 1997 OMB Standard for Federal Data on Race and Ethnicity [16]. We used the following categories for race: white, black/African American, Asian, Native Hawaiian or Other Pacific Islander, American Indian or Alaskan Native and other. Since a person could choose up to three races, only the first race code was used. For ethnicity, all the subcategories of Hispanic ethnicity were combined into one category of Hispanic ethnicity. The final racial/ethnic distributions for the 2006 death data for California were as follows: $83.6 \%$ white, $9.9 \%$ black, $5.4 \%$ Asian, 2.3\% Native Hawaiian/PI, 0.5\% American Indian or
AN, $0.2 \%$ other. Approximately $16 \%$ of the total deaths were of people of Hispanic ethnicity. For publication purposes only deaths due to white, black and Asian will be reported due to small cell sizes for the other race categories. Alcoholattributable deaths were estimated for each of the racial categories and then again separately for those reporting Hispanic ethnicity.

\section{Age and Sex}

Deaths were grouped into 5-year age groupings. Alcoholattributable deaths for illnesses or chronic conditions were captured from age 20 and older except those conditions specifically affecting infants and children due to the direct consumption of alcohol by the mother (i.e., fetal alcohol syndrome; fetus and newborn affected by the maternal use of alcohol; low birth weight, prematurity, and intrauterine growth retardation.) Alcohol-attributable deaths for injuries and violence were captured beginning from age 15 with the exception of the following two conditions - motor-vehicle traffic crashes and child maltreatment. Due to the availability of FARS data, alcohol-attributable deaths due to motorvehicle traffic crashes was estimated for all ages. Deaths due to child maltreatment were captured for individuals aged 14 and younger. Starting with age 15, these deaths are classified as homicide. Separate estimates were calculated for alcoholattributable deaths due to exposure to alcohol for individuals under age 21 .

Alcohol-attributable deaths were estimated separately for males and females for all injuries and illnesses except for breast cancer and spontaneous abortion deaths which were estimated only for women and prostate cancer was estimated only for men.

\section{Missing Information}

The following sociodemographic information was missing from individuals in the Death Statistical Master File: 49 did not have an age listed, 530 did not have a race code or refused to answer, and 195 did not report Hispanic ethnicity or refused to answer.

The ARDI tool requires information related to age and sex to calculate alcohol-attributable deaths. Because there were 49 individuals that did not have an age listed, these were deleted from the dataset. However, individuals without information related to race or ethnicity were not deleted from the dataset as long as both information regarding age and sex was complete. These individuals are included in the age- and sex-specific results only. The final sample size was 239,368 .

\section{Nonfatal Illnesses and Injuries}

\section{Sources}

To estimate the number of nonfatal illnesses and injuries in California for 2006, data from the California Office of Statewide Health Planning and Development Patient Discharge Data (PDD) set were used. This dataset contains information on all hospital discharges in the state of California including diagnosis, treatment and type of hospital utilized. To identify alcohol-attributable hospitalizations, the primary diagnosis field was used for nonfatal illnesses and the primary injury E-code for injuries. However, the state of California allows for both a primary diagnosis for an illness and a primary injury E-code to be used for the same hospital visit if applicable. To avoid double 
counting alcohol-attributable hospitalizations for which both an injury and illness are listed for the same visit, the injury diagnosis (E-code) was used as the underlying reason for the hospital visit. The reasoning is that individuals are more likely to visit the hospital due to an injury and then subsequently be treated for an illness as well (Steve Wirtz, Research Scientist at the California Department of Health Services, e-mail communication, April 2009).
The ARDI system was used to apply alcohol-attributable fractions for nonfatal illnesses to the PDD. A crosswalk of ICD-10 to ICD-9 codes included in the ARDI system was used to identify the current alcohol-attributable conditions in the PDD. The source for alcohol-attributable fractions for nonfatal injuries were obtained from an analysis by Miller and colleagues [17].

Table 1. Sources for Number of Cases and Alcohol-Attributable Fractions

\begin{tabular}{|c|c|c|}
\hline & Source of Numbers of Cases & Source of Alcohol-Attributable Fractions \\
\hline \hline Illness (fatal and nonfatal) & $\begin{array}{c}\text { Patient Discharge Data set 2006, California Death } \\
\text { Statistical Master File 2006 }\end{array}$ & ARDI \\
\hline Injury (fatal and nonfatal) & $\begin{array}{c}\text { Patient Discharge Data set 2006, California Death } \\
\text { Statistical Master File 2006 }\end{array}$ & Fatality Analysis Reporting System et al. [17] paper \\
\hline Traffic collisions (fatal and nonfatal) & $\begin{array}{c}\text { Patient Discharge Data set 2006, California Death } \\
\text { Statistical Master File 2006 }\end{array}$ \\
\hline
\end{tabular}

Table 2. Total Number of Alcohol-Attributable Illness Deaths by Sex, Hispanic Ethnicity and Race for California, 2006

\begin{tabular}{|c|c|c|c|c|c|c|c|c|}
\hline \multirow{2}{*}{ Condition } & \multirow{2}{*}{ Total } & \multicolumn{2}{|c|}{ Sex } & \multirow{2}{*}{$\begin{array}{l}\text { Hispanic } \\
\text { Ethnicity }\end{array}$} & \multicolumn{4}{|c|}{ Race } \\
\hline & & Male & Female & & White & Black & Asian & Other* \\
\hline \multicolumn{9}{|l|}{ Malignant neoplasms } \\
\hline Breast cancer (females only) & 39 & - & 39 & 7 & 32 & 3 & 2 & 1 \\
\hline Esophageal cancer & 40 & 35 & 5 & 4 & 35 & 2 & 2 & 0 \\
\hline Laryngeal cancer & 19 & 16 & 3 & 4 & 15 & 2 & 1 & 0 \\
\hline Liver cancer & 111 & 80 & 31 & 35 & 76 & 9 & 21 & 5 \\
\hline Oropharyngeal cancer & 36 & 30 & 6 & 6 & 30 & 3 & 2 & 1 \\
\hline Prostate cancer & 22 & 22 & - & 3 & 18 & 2 & 1 & 0 \\
\hline \multicolumn{9}{|l|}{ Neuro-psychiatric conditions } \\
\hline Alcohol abuse & 308 & 247 & 61 & 34 & 273 & 13 & 11 & 8 \\
\hline Alcohol dependence syndrome & 597 & 470 & 127 & 68 & 526 & 41 & 12 & 11 \\
\hline Alcoholic psychosis & 97 & 75 & 22 & 11 & 86 & 8 & 0 & 3 \\
\hline Degeneration of nervous system due to alcohol & 17 & 15 & 2 & 2 & 15 & 1 & 0 & 1 \\
\hline Epilepsy & 25 & 14 & 11 & 6 & 20 & 4 & 1 & 0 \\
\hline \multicolumn{9}{|l|}{ Cardiovascular diseases } \\
\hline Alcohol cardiomopathy & 81 & 70 & 11 & 13 & 68 & 6 & 3 & 4 \\
\hline Esophageal varices & 5 & 4 & 1 & 0 & 4 & 0 & 2 & 0 \\
\hline Hypertension & 194 & 103 & 91 & 44 & 151 & 26 & 11 & 6 \\
\hline Ischemic heart disease & 82 & 55 & 27 & 13 & 68 & 6 & 4 & 2 \\
\hline Stroke hemorrhagic & 188 & 154 & 34 & 48 & 140 & 16 & 20 & 12 \\
\hline Stroke ischemic & 39 & 28 & 11 & 7 & 32 & 2 & 3 & 1 \\
\hline Superventricular cardiac dysrthymia & 20 & 9 & 11 & 2 & 18 & 1 & 1 & 1 \\
\hline \multicolumn{9}{|l|}{ Digestive diseases } \\
\hline Alcoholic liver disease & 2701 & 1975 & 726 & 297 & 2399 & 152 & 68 & 64 \\
\hline Alcohol-induced chronic pancreatitis & 21 & 16 & 5 & 4 & 17 & 2 & 1 & 1 \\
\hline Chronic pancreatitis & 47 & 23 & 24 & 10 & 36 & 6 & 3 & 2 \\
\hline Acute pancreatitis & 60 & 34 & 26 & 10 & 50 & 4 & 3 & 2 \\
\hline Liver cirrhosis unspecified & 633 & 343 & 290 & 95 & 537 & 38 & 37 & 17 \\
\hline $\begin{array}{l}\text { Conditions during pregnancy or perinatal period } \\
\text { Low birth weight permaturity IUGR death }\end{array}$ & 15 & 10 & 5 & 4 & 10 & 3 & 1 & 0 \\
\hline Total & 5397 & 3828 & 1569 & 727 & 4656 & 350 & 210 & 142 \\
\hline
\end{tabular}

*Includes American Indian, Alaskan Natives, Hawaiian and Pacific Islander. 


\section{Race/Ethnicity}

For the PDD file, the race and ethnicity fields were coded to pre-determined racial and ethnic categories. Unfortunately, fewer racial categories were coded in the PDD file as are recommended by the 1997 OMB guidelines. For example, the racial category of Asian has been combined with Hawaiian and other Pacific Islander. The final racial distributions for the 2006 PDD were as follows: $54 \%$ white, $5 \%$ black, $0.1 \% \%$ American Indian or Alaskan Native, 5\% Native Hawaiian, Pacific Islander and Asian, $10 \%$ other. Approximately, $30 \%$ of the total sample identified as Hispanic ethnicity. Hospitalizations were only broken out for whites and blacks due to small cell sizes for the other race categories. Alcohol-attributable hospitalizations were estimated for each of the racial categories and then again separately for those of Hispanic ethnicity.

\section{Age and Sex}

The same age and sex categories and guidelines mentioned above used for fatal illnesses and injuries were also applied to hospitalizations.

\section{Missing and Censored Information}

The following sociodemographic information was missing or unknown for individuals in the PDD: 49 did not indicate a sex; 15,268 did not have ethnicity listed; and 394,117 did not have race listed or was labeled unknown. As described previously, due to ARDI restrictions, individuals without information related to race or ethnicity were not deleted from the dataset as long as information regarding both age and sex was complete. These individuals are only included in the age- and sex-specific results.

In addition, the California Office of Statewide Health Planning and Development has taken steps to protect confidentiality and has masked a certain percentage of sociodemographic information contained in the PDD. The following proportion of each demographic variable was masked in the dataset: $6.8 \%$ of age (coded in 5-year age groups), $18.3 \%$ of sex, $30.5 \%$ of ethnicity, and $26.6 \%$ of race (note: for some individuals multiple fields were masked). Individuals with either age or sex masked could not be included in the analysis. However, individuals with only race or ethnicity masked are included in the age- and sex-specific estimates of alcohol-attributable hospitalizations. The final sample size to determine alcoholattributable hospitalizations was 3,266,470.

Table 3. Total Number of Alcohol-Attributable Illness Deaths by Sex and Age Groups for California, 2006

\begin{tabular}{|c|c|c|c|c|c|c|c|c|c|c|c|c|c|c|c|}
\hline \multirow{2}{*}{ Condition } & \multicolumn{5}{|c|}{ Male } & \multicolumn{5}{|c|}{ Female } & \multicolumn{5}{|c|}{ Total } \\
\hline & $0-19$ & 20-34 & $35-49$ & $50-64$ & $65+$ & $0-19$ & $20-34$ & $35-49$ & $50-64$ & $65+$ & $0-19$ & 20-34 & $35-49$ & $50-64$ & $65+$ \\
\hline \multicolumn{16}{|l|}{ Malignant neoplasms } \\
\hline Breast cancer (females only) & - & - & - & - & - & 0 & 1 & 5 & 12 & 21 & 0 & 1 & 5 & 13 & 21 \\
\hline Esophageal cancer & 0 & 0 & 1 & 12 & 22 & 0 & 0 & 0 & 1 & 4 & 0 & 0 & 2 & 14 & 26 \\
\hline Laryngeal cancer & 0 & 0 & 1 & 4 & 11 & 0 & 0 & 0 & 1 & 2 & 0 & 0 & 1 & 5 & 13 \\
\hline Liver cancer & 0 & 0 & 6 & 31 & 42 & 0 & 0 & 2 & 7 & 22 & 0 & 1 & 8 & 38 & 64 \\
\hline Oropharyngeal cancer & 0 & 0 & 2 & 12 & 16 & 0 & 0 & 0 & 1 & 4 & 0 & 0 & 3 & 13 & 20 \\
\hline Prostate cancer & 0 & 0 & 0 & 2 & 20 & - & - & - & - & - & 0 & 0 & 0 & 2 & 20 \\
\hline \multicolumn{16}{|l|}{ Neuro-psychiatric conditions } \\
\hline Alcohol abuse & 0 & 29 & 105 & 82 & 31 & 0 & 5 & 20 & 28 & 8 & 0 & 34 & 125 & 110 & 39 \\
\hline Alcohol dependence syndrome & 0 & 23 & 139 & 242 & 66 & 0 & 5 & 36 & 51 & 35 & 0 & 28 & 175 & 293 & 101 \\
\hline Alcoholic psychosis & 0 & 1 & 23 & 24 & 27 & 0 & 0 & 5 & 9 & 8 & 0 & 1 & 28 & 33 & 35 \\
\hline Degeneration of nervous system due to alcohol & 0 & 1 & 2 & 6 & 6 & 0 & 0 & 0 & 1 & 1 & 0 & 1 & 2 & 7 & 7 \\
\hline Epilepsy & 0 & 3 & 4 & 3 & 3 & 0 & 2 & 2 & 5 & 3 & 0 & 5 & 6 & 8 & 6 \\
\hline \multicolumn{16}{|l|}{ Cardiovascular diseases } \\
\hline Alcohol cardiomopathy & 0 & 3 & 29 & 29 & 9 & 0 & 0 & 3 & 5 & 3 & 0 & 3 & 32 & 34 & 12 \\
\hline Esophageal varices & 0 & 0 & 2 & 12 & 2 & 0 & 0 & 0 & 0 & 1 & 0 & 0 & 2 & 0 & 3 \\
\hline Hypertension & 0 & 1 & 10 & 24 & 69 & 0 & 0 & 3 & 9 & 79 & 0 & 1 & 13 & 32 & 141 \\
\hline Ischemic heart disease & 0 & 0 & 3 & 10 & 42 & 0 & 0 & 0 & 2 & 24 & 0 & 0 & 3 & 12 & 66 \\
\hline Portal hypertension & 0 & 0 & 0 & 1 & 1 & 0 & 0 & 0 & 0 & 0 & 0 & 0 & 0 & 1 & 1 \\
\hline Stroke hemorrhagic & 0 & 3 & 21 & 40 & 90 & 0 & 0 & 3 & 7 & 24 & 0 & 3 & 24 & 47 & 114 \\
\hline Stroke ischemic & 0 & 0 & 1 & 3 & 23 & 0 & 0 & 0 & 1 & 10 & 0 & 0 & 1 & 4 & 33 \\
\hline Superventricular cardiac dysrthymia & 0 & 0 & 0 & 1 & 8 & 0 & 0 & 0 & 0 & 10 & 0 & 0 & 0 & 1 & 20 \\
\hline \multicolumn{16}{|l|}{ Digestive diseases } \\
\hline Alcoholic liver disease & 0 & 38 & 522 & 973 & 442 & 0 & 19 & 218 & 317 & 172 & 0 & 57 & 740 & 1290 & 614 \\
\hline Alcohol-induced chronic pancreatitis & 0 & 4 & 4 & 4 & 4 & 0 & 0 & 4 & 1 & 0 & 0 & 4 & 8 & 5 & 4 \\
\hline Chronic pancreatitis & 0 & 0 & 8 & 5 & 9 & 0 & 0 & 1 & 8 & 14 & 0 & 0 & 9 & 13 & 24 \\
\hline Acute pancreatitis & 0 & 5 & 8 & 9 & 12 & 0 & 1 & 3 & 3 & 19 & 0 & 6 & 11 & 12 & 31 \\
\hline Liver cirrhosis unspecified & 0 & 5 & 56 & 150 & 132 & 0 & 3 & 37 & 87 & 163 & 0 & 8 & 94 & 236 & 295 \\
\hline $\begin{array}{l}\text { Conditions during pregnancy or perinatal period } \\
\text { Low birth weight prematurity IUGR death }\end{array}$ & 10 & - & - & - & - & 5 & - & - & - & - & 15 & - & - & - & - \\
\hline Total & 10 & 116 & 947 & 1679 & 1087 & 5 & 36 & 342 & 556 & 627 & 15 & 153 & 1292 & 2223 & 1710 \\
\hline
\end{tabular}


Table 4. Total Number of Alcohol-Attributable Injury Deaths by Sex, Hispanic Ethnicity and Race for California, 2006

\begin{tabular}{|c|c|c|c|c|c|c|c|c|}
\hline \multirow{2}{*}{ Condition } & \multirow{2}{*}{ Total } & \multicolumn{2}{|c|}{ Sex } & \multirow{2}{*}{$\begin{array}{l}\text { Ethnicity } \\
\text { Hispanic }\end{array}$} & \multicolumn{4}{|c|}{ Race } \\
\hline & & Male & Female & & White & Black & Asian & Other* \\
\hline \multicolumn{9}{|l|}{ Unintentional injury } \\
\hline Air space transport & 18 & 15 & 3 & 1 & 17 & 0 & 1 & 0 \\
\hline Alcohol poisoning & 39 & 32 & 7 & 5 & 34 & 3 & 1 & 1 \\
\hline Aspiration & 25 & 14 & 11 & 2 & 23 & 1 & 1 & 0 \\
\hline Drowning & 135 & 103 & 31 & 27 & 107 & 9 & 14 & 2 \\
\hline Falls & 566 & 336 & 230 & 69 & 498 & 19 & 32 & 17 \\
\hline Fire & 83 & 48 & 35 & 16 & 66 & 11 & 3 & 2 \\
\hline Firearm & 13 & 12 & 1 & 5 & 8 & 3 & 1 & 1 \\
\hline Hypothermia & 11 & 8 & 3 & 0 & 11 & 0 & 0 & 0 \\
\hline Occupational and machine & 11 & 11 & 0 & 1 & 10 & 0 & 0 & 0 \\
\hline Other road and vehicle crashes & 60 & 48 & 12 & 8 & 52 & 4 & 3 & 1 \\
\hline Poisoning & 830 & 548 & 282 & 127 & 702 & 97 & 12 & 17 \\
\hline Water transport & 7 & 5 & 2 & 2 & 5 & 1 & 0 & 0 \\
\hline Motor-vehicle traffic crashes & 1457 & 1149 & 308 & 239 & 1210 & 105 & 62 & 54 \\
\hline \multicolumn{9}{|l|}{ Violence } \\
\hline Child maltreatment & 21 & 12 & 8 & 6 & 14 & 5 & 1 & 0 \\
\hline Homicide & 1174 & 999 & 175 & 443 & 730 & 358 & 53 & 27 \\
\hline Suicide & 772 & 597 & 175 & 98 & 674 & 31 & 49 & 18 \\
\hline Total & 5222 & 3937 & 1283 & 1049 & 4161 & 647 & 233 & 140 \\
\hline
\end{tabular}

*Includes American Indian, Alaskan Natives, Hawaiian and Pacific Islander.

Table 5. Total Number of Alcohol-Attributable Injury Deaths by Sex and Age Groups for California, 2006

\begin{tabular}{|c|c|c|c|c|c|c|c|c|c|c|c|c|c|c|c|}
\hline \multirow{2}{*}{ Condition } & \multicolumn{5}{|c|}{ Male } & \multicolumn{5}{|c|}{ Female } & \multicolumn{5}{|c|}{ Total } \\
\hline & $0-19$ & $20-34$ & $35-49$ & $50-64$ & $65+$ & $0-19$ & $20-34$ & $35-49$ & $50-64$ & $65+$ & $0-19$ & $20-34$ & $35-49$ & $50-64$ & $65+$ \\
\hline Unintentional injury & & & & & & & & & & & & & & & \\
\hline Air space transport & 0 & 2 & 4 & 6 & 3 & 0 & 0 & 1 & 1 & 0 & 0 & 2 & 5 & 8 & 3 \\
\hline Alcohol poisoning & 1 & 10 & 12 & 9 & 0 & 0 & 0 & 6 & 1 & 0 & 1 & 10 & 18 & 10 & 0 \\
\hline Aspiration & 0 & 1 & 2 & 4 & 7 & 0 & 0 & 2 & 1 & 8 & 0 & 1 & 3 & 5 & 15 \\
\hline Drowning & 9 & 31 & 28 & 18 & 17 & 1 & 5 & 8 & 5 & 11 & 10 & 36 & 36 & 24 & 28 \\
\hline Falls & 3 & 22 & 38 & 56 & 217 & 1 & 4 & 9 & 17 & 199 & 4 & 26 & 47 & 73 & 416 \\
\hline Fire & 0 & 3 & 9 & 18 & 17 & 1 & 3 & 5 & 9 & 17 & 1 & 6 & 14 & 27 & 34 \\
\hline Firearm & 3 & 6 & 2 & 0 & 1 & 0 & 0 & 0 & 0 & 0 & 3 & 6 & 2 & 0 & 1 \\
\hline Hypothermia & 2 & 1 & 3 & 2 & 1 & 1 & 0 & 0 & 1 & 1 & 3 & 1 & 3 & 3 & 2 \\
\hline Occupational and machine & 0 & 2 & 3 & 3 & 2 & 0 & 0 & 0 & 0 & 0 & 0 & 2 & 3 & 3 & 2 \\
\hline Other road and vehicle crashes & 3 & 11 & 14 & 14 & 7 & 0 & 2 & 3 & 3 & 3 & 4 & 13 & 17 & 16 & 10 \\
\hline Poisoning & 8 & 105 & 253 & 166 & 16 & 5 & 42 & 119 & 99 & 17 & 14 & 147 & 372 & 264 & 33 \\
\hline Water transport & 0 & 1 & 2 & 1 & 1 & 0 & 1 & 0 & 1 & 0 & 0 & 2 & 2 & 1 & 1 \\
\hline Motor-vehicle traffic crashes & 108 & 497 & 328 & 169 & 46 & 42 & 114 & 89 & 38 & 24 & 150 & 611 & 417 & 208 & 70 \\
\hline Violence & & & & & & & & & & & & & & & \\
\hline Child maltreatment & 13 & - & - & - & - & 8 & - & - & - & - & 21 & - & - & - & - \\
\hline Homicide & 193 & 499 & 203 & 86 & 19 & 19 & 58 & 52 & 31 & 14 & 212 & 557 & 255 & 117 & 33 \\
\hline Suicide & 27 & 142 & 169 & 146 & 113 & 9 & 29 & 58 & 51 & 29 & 36 & 171 & 227 & 196 & 142 \\
\hline Total & 370 & 1333 & 1070 & 698 & 467 & 87 & 258 & 352 & 258 & 323 & 459 & 1591 & 1421 & 955 & 790 \\
\hline
\end{tabular}


Table 6. Rate of Alcohol-Attributable Illness and Injury Deaths for Select Conditions Per 1,000,000 Persons by Sex, Hispanic Ethnicity and Race for California, 2006

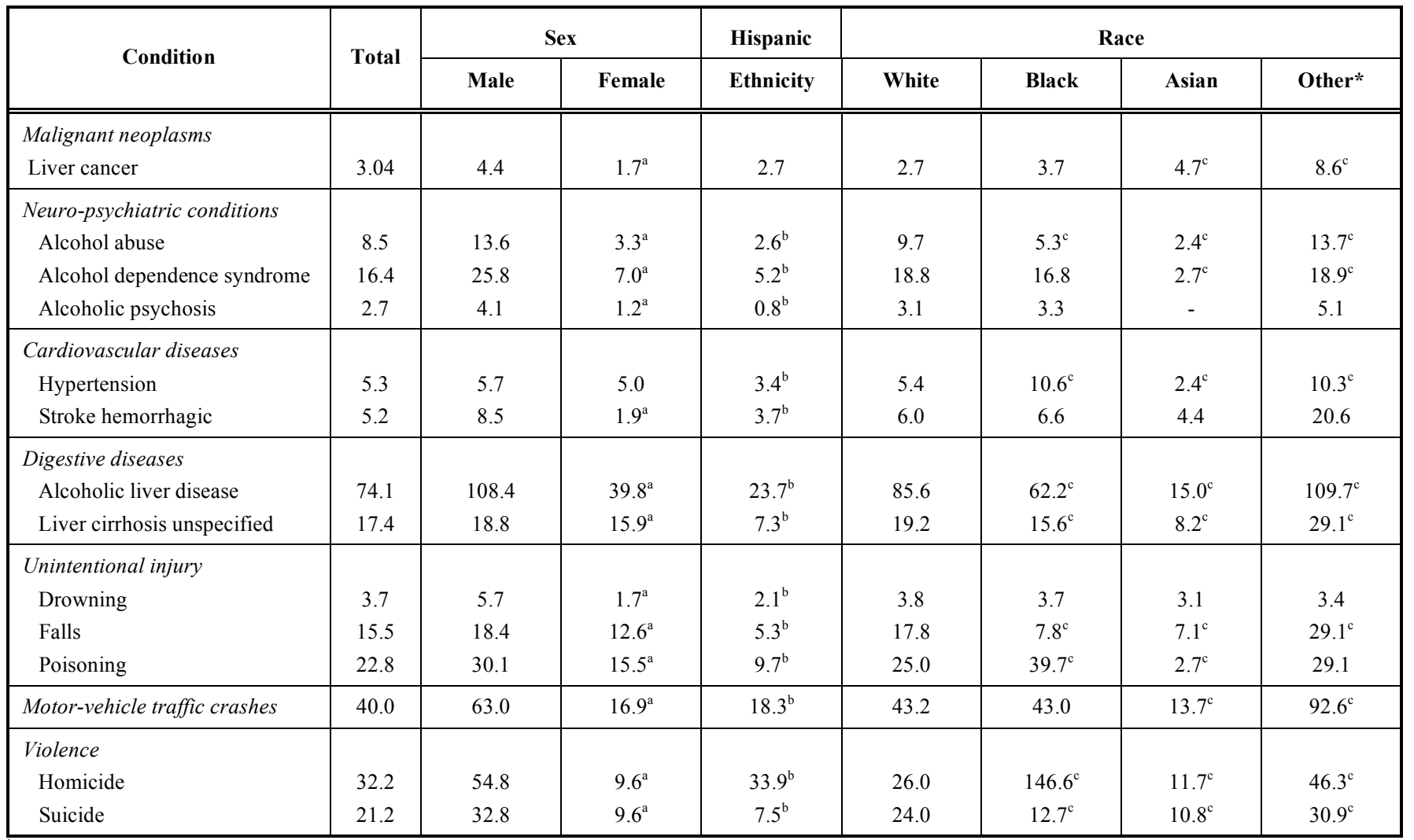

"Includes Hawaiian, Pacific Islander, Alaskan Native, and American Indian.

${ }^{a}$ Statistically significant difference from males $(\mathrm{p}<0.05)$.

${ }^{\mathrm{b}}$ Statistically significant difference from Non-Hispanics $(\mathrm{p}<0.05)$.

${ }^{\mathrm{c}}$ Statistically significant difference from whites $(\mathrm{p}<0.05)$.

\section{Analysis}

\section{Alcohol-Related Measures}

For each alcohol-related diagnosis, total number of deaths and hospitalizations were entered into ARDI. The number of deaths for each diagnosis was multiplied by the corresponding alcohol-attributable fraction to estimate alcohol-attributable deaths and nonfatal hospitalizations by sex, age, and race/ethnicity. Alcohol-attributable deaths and hospitalizations were calculated separately by sex, age groups, Hispanic ethnicity, and race. For the leading alcoholattributable deaths and alcohol-attributable hospitalizations, rates were computed by the direct method using the population of California in 2000 as the standard population. Mortality and hospitalization rates were compared testing for the difference between independent rates. Differences were statistically significant at the .05 significance level.

\section{RESULTS}

\section{Alcohol-Attributable Deaths}

For 2006, there were 10,619 deaths due to alcohol use in the state of California. Of these deaths, 5397 were due to illnesses or chronic conditions (51\% of total deaths). Alcoholic liver disease (2701 deaths) was the most common illness death resulting in about 74 deaths per $1,000,000$ persons in 2006. The top three leading causes of illness deaths were alcoholic liver disease, liver cirrhosis (633 deaths; 17 deaths per $1,000,000$ persons) and alcohol dependence syndrome (597 deaths; 16 deaths per 1,000,000 persons). About $28 \%$ of injury deaths were due to motorvehicle traffic crashes (1457 deaths; 40 deaths per 1,000,000 persons). The top three leading causes of injury deaths were motor-vehicle traffic crashes, homicide (1174 deaths; 32 deaths per 1,000,000 persons) and poisoning (830 deaths; 23 deaths per 1,000,000 persons).

\section{Sex and Age Differences}

For men, the second leading cause of alcohol-attributable illness death was alcohol dependence syndrome (470 deaths) and the third leading cause was liver cirrhosis, unspecified (343 deaths) (Table 2). Overall, deaths for illnesses that were alcohol-attributable peaked between the ages of 50-64 years old (Table 3). However, for women, there were more alcohol-attributable deaths occurring after age 65. For alcohol-attributable deaths due to injuries, suicide was the third leading cause of death for men (597 deaths; 33 deaths per 1,000,000 persons) while for women suicide and homicide were the fourth leading cause of death (175 deaths each; 10 deaths per $1,000,000$ persons) (Table 4). For women, alcohol-attributable death due to falls was the third leading cause (230 deaths). Overall, alcohol-attributable injury deaths peaked between ages 20 to 34 years, except for females who had more alcohol-related injury deaths from 35 to 49 years mostly due to poisoning (119 deaths) and suicide (58 deaths) (Table 5). Deaths due to poisoning more 
Table 7. Total Number of Alcohol-Attributable Deaths Due to Exposure to Alcohol for Under Age 21 by sex for California, 2006

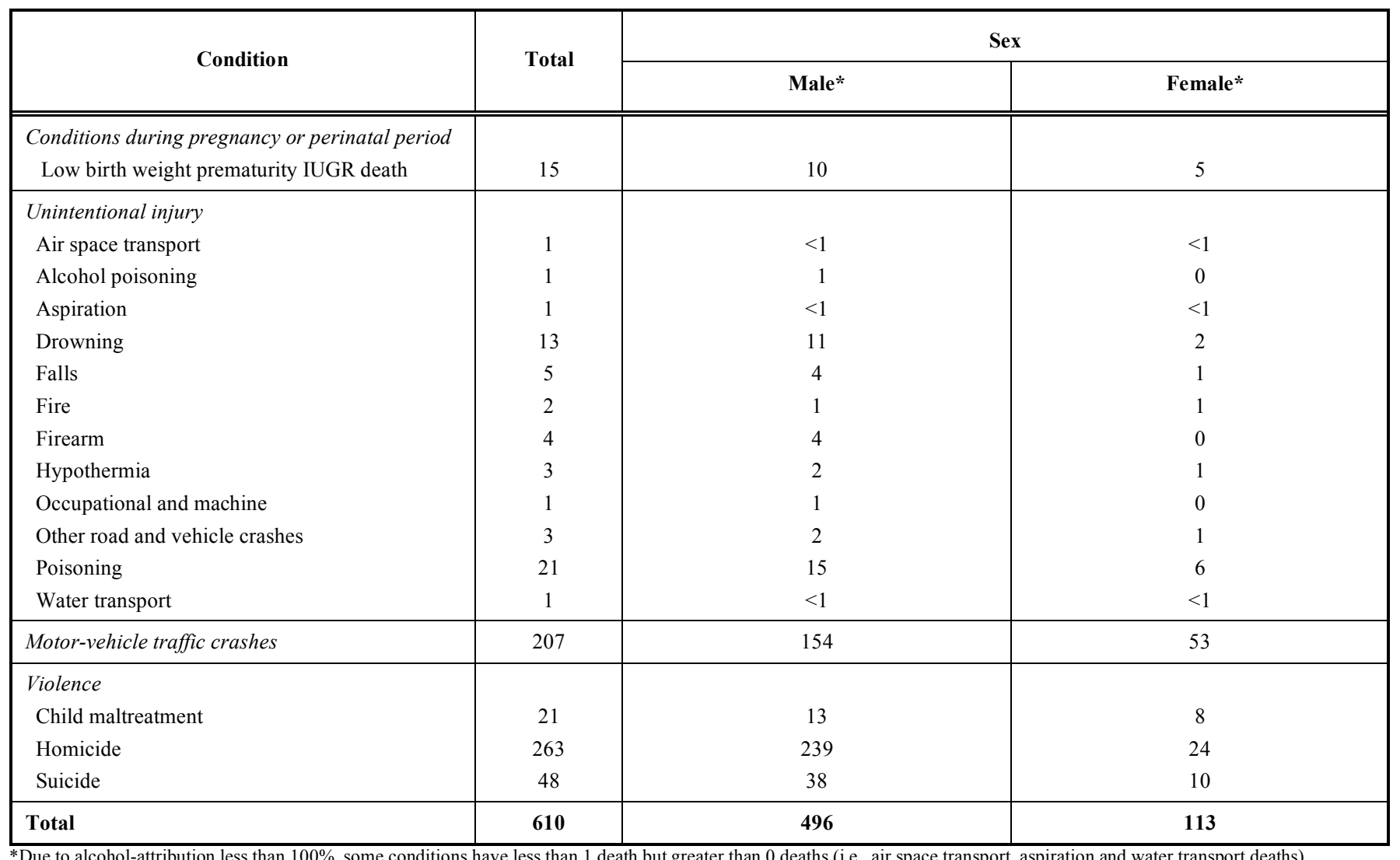

*Due to alcohol-attribution less than $100 \%$, some conditions have less than 1 death but greater than 0 deaths (i.e., air space transport, aspiration and water transport deaths).

commonly occur among 35 to 49 year olds than any other age group. Alcohol-attributable motor-vehicle traffic crash deaths and homicides peaked for both males and females between ages 20 to 34 years old (125 deaths per 1,000,000 persons and 29 deaths per 1,000,000 persons, respectively) (Table 13).

\section{$\underline{\text { Racial/Ethnic Differences }}$}

For most conditions, alcohol-attributable deaths by racial and ethnic groups had similar overall patterns in regards to the common causes of death (Table 2). The total number of deaths for each condition reflected the current population size for each racial/ethnic group. However, after whites, Asians had the second highest number of deaths due to liver cancer (21 deaths) when compared to other racial groups. For the leading causes of deaths, whites had statistically significant higher alcohol-attributable death rates than blacks except for the following conditions: hypertension, poisoning, and homicide (Table 6). Asians were more likely to die from falls and drowning than blacks; however, these differences were not statistically significant (data not shown). For alcohol-attributable deaths due to injuries, blacks and Hispanics were more likely to die from homicide (358 and 443 deaths) than motor-vehicle traffic crashes (105 and 239 deaths) (Table 4). The alcohol-attributable death rate for homicide was significantly higher for Hispanics than nonHispanics (data not shown).

\section{Under 21}

The top three leading alcohol-attributable deaths for individuals under age 21 were homicide (263 deaths), motor- vehicle traffic crashes (207 deaths), and suicide (48 deaths). Forty-seven percent of all alcohol-attributable deaths for underage youth and young adults were due to homicide or child maltreatment (Table 7). For underage females, the leading cause of death was motor-vehicle traffic crashes (53 deaths) followed by homicide (24 deaths) and suicide (10 deaths)

\section{Alcohol-Attributable Hospitalizations}

For 2006, there were 72,771 hospitalizations due to alcohol use in the state of California. There were 34,292 hospitalizations due to illnesses or chronic conditions $(47 \%$ of total hospitalizations). About $22 \%$ of these hospitalizations were due to alcoholic liver disease (7374 hospitalizations; 202 deaths per 1,000,000 persons). The top three leading causes of illnesses were alcoholic liver disease, alcoholic psychosis (7173 hospitalizations; 197 deaths per $1,000,000$ persons) and acute pancreatitis (4976 hospitalizations; 136 deaths per $1,000,000$ persons). There were 38,479 hospitalizations due to injuries $(53 \%$ of total hospitalizations). About $56 \%$ of these injury hospitalizations were due to falls $(21,616$ hospitalizations). The top three leading causes of hospitalizations were falls, motor-vehicle traffic crashes $(5219$ hospitalizations 143 deaths per 1,000,000 persons), assault (2745 hospitalizations; 75 deaths per $1,000,000$ persons) and attempted suicide (2705 hospitalizations; 74 deaths per 1,000,000 persons).

\section{$\underline{\text { Sex and Age Differences }}$}

Overall, more than half of the alcohol-attributable hospitalizations due to illnesses were suffered by men (Table 
Table 8. Total Hospitalizations for Alcohol-Attributable Illness by Sex, Hispanic Ethnicity and Race for California, 2006

\begin{tabular}{|c|c|c|c|c|c|c|c|}
\hline \multirow{2}{*}{ Condition } & \multirow{2}{*}{ Total } & \multicolumn{2}{|c|}{ Sex } & \multirow{2}{*}{$\begin{array}{l}\text { Ethnicity } \\
\text { Hispanic }\end{array}$} & \multicolumn{3}{|c|}{ Race } \\
\hline & & Male & Female & & White & Black & Other* \\
\hline \multicolumn{8}{|l|}{ Malignant neoplasms } \\
\hline Breast cancer (females only) & 63 & - & 63 & 7 & 45 & 3 & 3 \\
\hline Esophageal cancer & 27 & 23 & 4 & 3 & 20 & 1 & 2 \\
\hline Laryngeal cancer & 26 & 22 & 4 & 4 & 17 & 2 & 1 \\
\hline Liver cancer & 100 & 76 & 24 & 19 & 48 & 7 & 20 \\
\hline Oropharyngeal cancer & 53 & 44 & 9 & 6 & 39 & 3 & 2 \\
\hline Prostate cancer & 41 & 41 & - & 4 & 30 & 3 & 1 \\
\hline \multicolumn{8}{|l|}{ Neuro-psychiatric conditions } \\
\hline Alcohol abuse & 666 & 446 & 220 & 109 & 489 & 40 & 8 \\
\hline Alcohol dependence syndrome & 4703 & 2997 & 1706 & 426 & 3797 & 148 & 45 \\
\hline Alcohol polyneuropathy & 53 & 36 & 17 & 4 & 38 & 4 & 1 \\
\hline Alcoholic psychosis & 7173 & 5472 & 1701 & 1123 & 5298 & 377 & 67 \\
\hline Epilepsy & 389 & 192 & 197 & 68 & 258 & 41 & 9 \\
\hline \multicolumn{8}{|l|}{ Cardiovascular diseases } \\
\hline Alcohol cardiomopathy & 97 & 89 & 8 & 15 & 73 & 3 & 1 \\
\hline Esophageal varices & 185 & 125 & 60 & 69 & 116 & 6 & 9 \\
\hline Hypertension & 531 & 291 & 240 & 109 & 275 & 94 & 38 \\
\hline Ischemic heart disease & 201 & 150 & 51 & 23 & 142 & 9 & 11 \\
\hline Portal hypertension & 108 & 65 & 43 & 31 & 74 & 4 & 4 \\
\hline Stroke hemorrhagic & 543 & 455 & 88 & 82 & 338 & 32 & 50 \\
\hline Stroke ischemic & 1940 & 1450 & 490 & 231 & 1385 & 120 & 114 \\
\hline Superventricular cardiac dysrthymia & 480 & 262 & 218 & 47 & 374 & 19 & 21 \\
\hline \multicolumn{8}{|l|}{ Digestive diseases } \\
\hline Alcoholic liver disease & 7374 & 5478 & 1896 & 2461 & 5077 & 344 & 176 \\
\hline Acute pancreatitis & 4976 & 2321 & 2655 & 1170 & 3236 & 409 & 216 \\
\hline Alcoholic gastritis & 658 & 490 & 168 & 166 & 442 & 45 & 9 \\
\hline Chronic pancreatitis & 1410 & 650 & 760 & 283 & 916 & 196 & 42 \\
\hline Gastroesophageal hemorrhage & 682 & 443 & 239 & 131 & 447 & 54 & 36 \\
\hline Liver cirrhosis unspecified & 1637 & 787 & 850 & 477 & 1080 & 66 & 119 \\
\hline \multicolumn{8}{|l|}{ Conditions during pregnancy or perinatal period } \\
\hline Low birth weight prematurity IUGR death & 84 & 52 & 32 & 30 & 47 & 5 & 4 \\
\hline Spontaneous abortion & 92 & - & 92 & 44 & 52 & 8 & 5 \\
\hline Total & 34292 & 22457 & 11835 & 7142 & 24153 & 2043 & 1014 \\
\hline
\end{tabular}

Includes Asian, Native Hawaiian, Pacific Islander, American Indian and Alaskan Native.

8), though slightly more than half $(52 \%)$ of the hospitalizations for injuries were for women. For women, acute pancreatitis was the leading reason for an alcoholattributable hospitalization (2655 hospitalizations), which resulted in a rate of 146 hospitalizations per $1,000,000$ persons and was significantly higher than the rate for men. Men were more likely to be hospitalized for alcohol dependence syndrome (2997) than for acute pancreatitis (2321). Overall, hospitalizations for alcohol-attributable illnesses peaked for most conditions between ages 35 to 49 years with the exception of alcoholic liver disease, which peaked between ages 50-64 years (Table 9). For alcoholattributable hospitalizations due to injuries, suicide attempt was the third leading cause for women ( 88 hospitalizations per $1,000,000$ persons) (Table 10). Slightly more women than men were hospitalized for suicide attempt (1606 vs 1099 hospitalizations) in 2006 and this difference was statistically significant (Table 11). Alcohol-attributable hospitalizations for injuries sustained due to motor-vehicle traffic crashes (1615 hospitalizations) or assault (1209 hospitalizations) were more common among 20 to 34 year olds. In addition, hospitalizations due to attempted suicide were more common among both men and women aged 35 to 49 years (936 hospitalizations).

\section{Race/Ethnic Differences}

For most conditions, alcohol-attributable hospitalizations for race and ethnicity followed the similar overall patterns. Hispanics had a similar number of hospitalizations for acute pancreatitis and alcoholic psychosis (1170 and 1123 hospitalizations, respectively) (Table 8). Whites were more likely to be hospitalized for alcoholic psychosis (5298 hospitalizations) than alcoholic liver disease (5077 hospitalizations). The third leading cause of hospitalizations for whites was alcohol dependence syndrome (3797 
Table 9. Total Alcohol-Attributable Hospitalizations for Illness by Sex and Age Groups for California, 2006

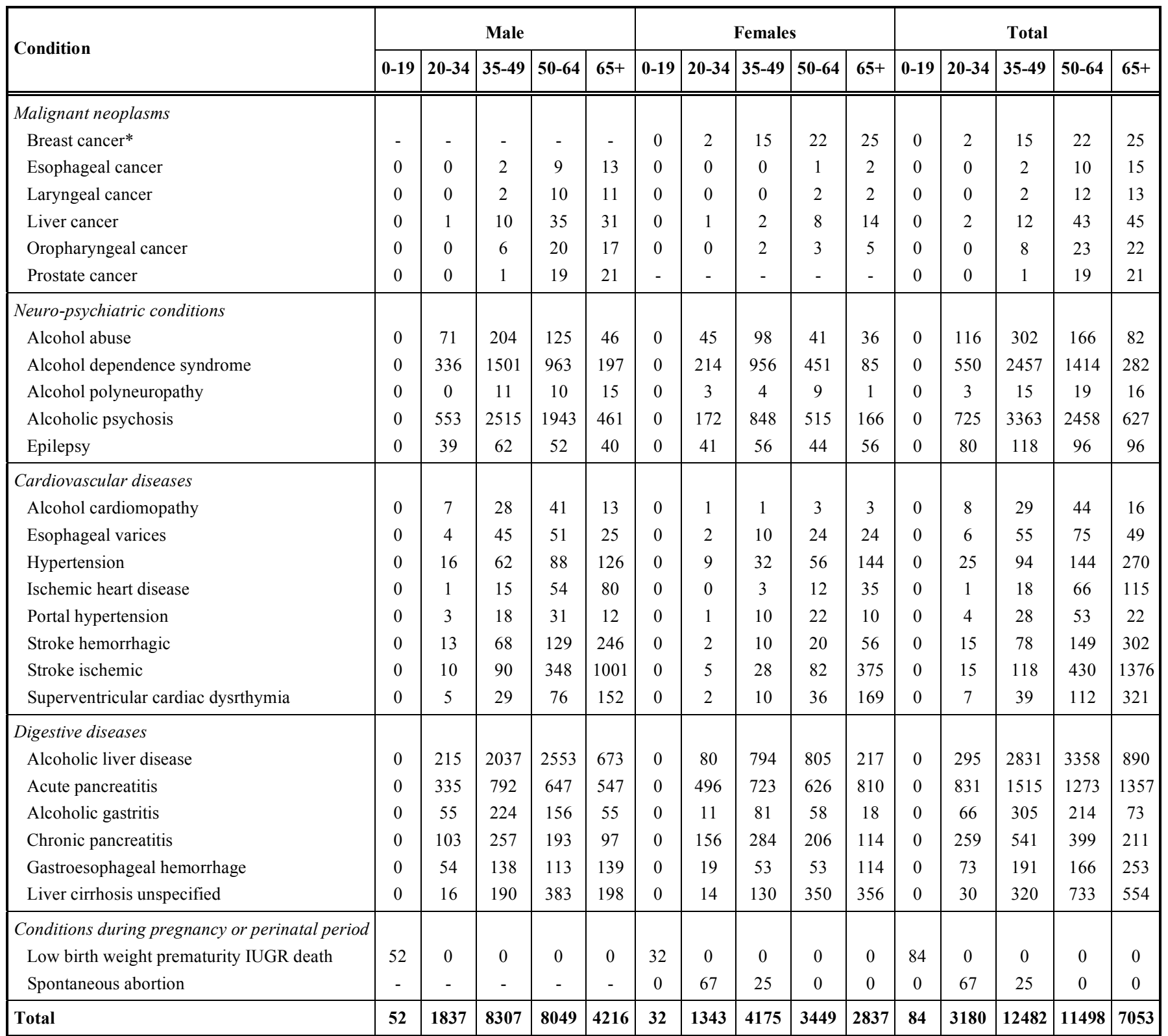

*Breast cancer hospitalizations are captured for females only.

hospitalizations). For most leading causes of alcoholattributable nonfatal hospitalizations, blacks had a statistically higher hospitalization rate than whites except for alcohol dependence syndrome, alcoholic psychosis, alcoholic liver disease and liver cirrhosis for which whites had a higher rate (Table 11). The patterns of alcoholattributable hospitalizations due to injuries were similar among the racial/ethnic groups as seen overall, except the second leading cause of hospitalizations for blacks was due to assault (447 hospitalizations; 183 deaths per 1,000,000 persons). The third leading cause of hospitalizations for whites was attempted suicide (1932 hospitalizations; 69 deaths per $1,000,000$ persons).

\section{Under 21}

The leading causes of alcohol-attributable hospitalizations for persons under age 21 were motor-vehicle traffic crashes (939 hospitalizations), assault (507 hospitalizations), and attempted suicide (384 hospitalizations) (Table 12). For most conditions, underage males were more likely to be hospitalized for alcoholattributable injuries than underage females. The exception was attempted suicide where females were more likely to be hospitalized than males (269 vs 115 hospitalizations, respectively). In fact, suicide attempt was the second leading alcohol-attributable hospitalization among females under age 21. Approximately $22 \%$ of all alcohol-attributable hospitalizations were due to assault or child maltreatment. Similar numbers of alcohol-attributable poisoning hospitalizations occurred for both males and females (34 for males and 38 for females).

\section{DISCUSSION}

For 2006, there were over 10,000 deaths and over 72,000 hospitalizations that were attributable to alcohol in 
Table 10. Total Alcohol-Attributable Hospitalizations for Injuries by Sex, Hispanic Ethnicity and Race for California, 2006

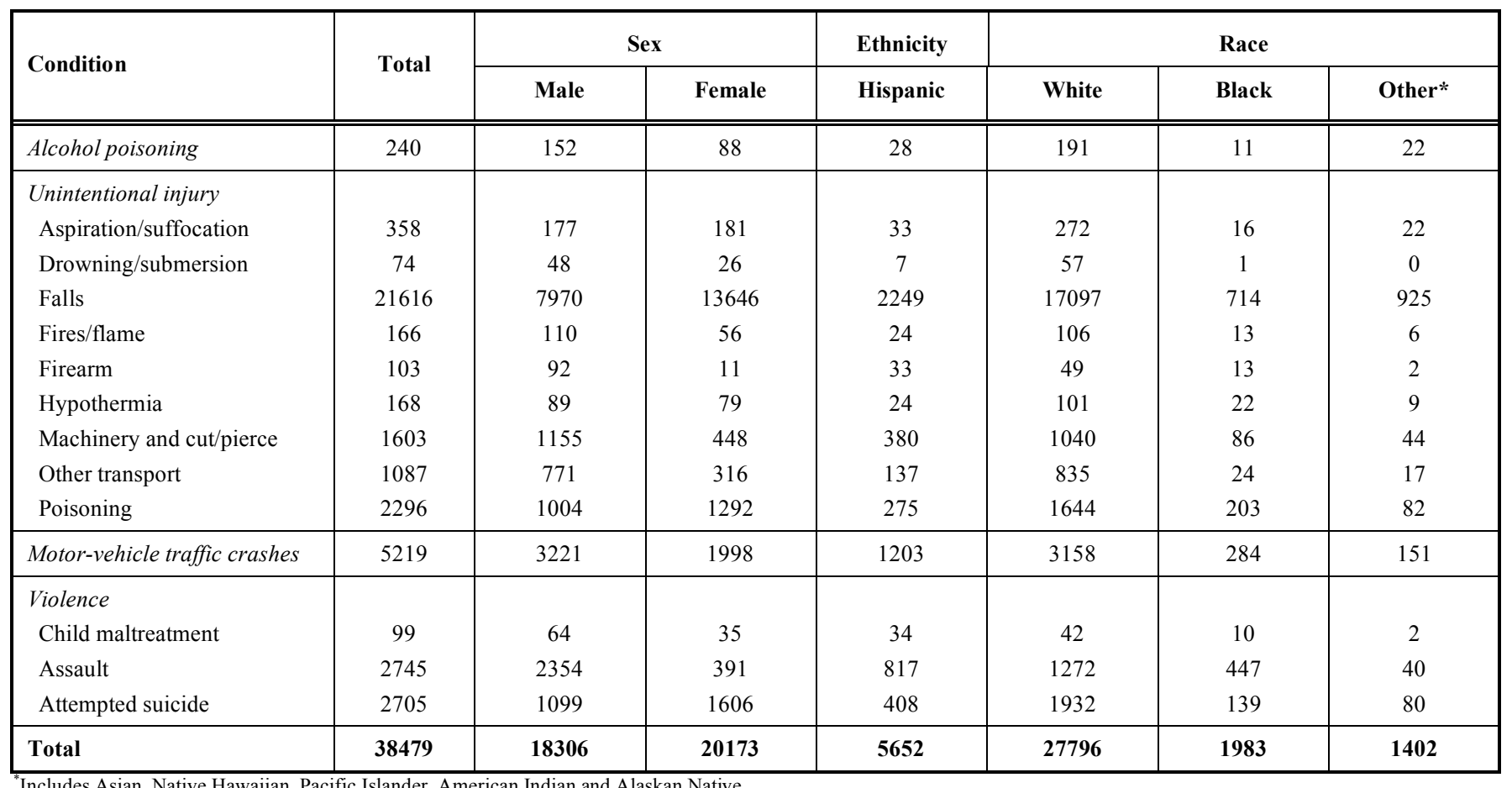

Includes Asian, Native Hawaiian, Pacific Islander, American Indian and Alaskan Native.

California. The majority of alcohol-attributable deaths and hospitalizations were due to chronic conditions or illnesses. Alcoholic liver disease was the most common illness-related cause of death and hospitalization. Alcohol-attributable motor-vehicle traffic crashes were the most common injury cause of death and falls were the most common cause of alcohol-attributable hospitalizations. The top three leading causes of alcohol-attributable illness deaths in California were similar to that found at the national level [3]. However, the top three leading cause of alcohol-attributable injury death in California were (in order) motor-vehicle traffic crashes, homicide and non-alcohol poisoning deaths. At the national level, suicide was the third leading alcoholattributable cause of injury death annually from 2001 to 2005 [3]. For California, suicide ranked fourth with 772 deaths. For youth under age 21, the leading cause of alcoholattributable deaths overall and for males was homicide, while motor-vehicle traffic crashes was the leading cause for females. At the national level from 2001-2005, the leading cause of death attributable to alcohol for this age group for both males and females was motor-vehicle traffic crashes followed by homicide [3]. Information is not available at the national level regarding frequency of alcohol-attributable nonfatal hospitalizations for the conditions included in this study.

Overall, more than half of the alcohol-attributable deaths for illnesses and injuries were suffered by men with nearly twice as many deaths occurring for both illnesses and injuries than women. About twice as many hospitalizations for illnesses were also reported by males compared to females; however the proportion of nonfatal hospitalizations for injuries was similar for both males and females. Women had a higher rate of nonfatal alcohol-attributable hospitalizations for acute pancreatitis, chronic pancreatitis, liver cirrhosis, epilepsy, falls, unintentional poisonings, and aspiration.

Most alcohol-attributable deaths due to illness peaked between ages 50 to 64 years old whereas most alcoholattributable deaths due to injuries peak during much younger ages. This is to be expected since the development of alcohol-related illnesses are usually the result of chronic forms of alcohol use while injury deaths tend to be due to single occasions of intoxication. The exception was alcoholattributable deaths due to falls which is largely age-driven. Most deaths and nonfatal hospitalizations due to this condition peaked among those aged 65 years and older. However, without an age-specific alcohol-attributable fraction for falls, it is difficult to interpret the true impact of alcohol use for this condition since individuals in the oldest age group, where falls are most prominent, are least likely to drink compared to other age groups [9]. More research into an age-specific alcohol attributable fraction for deaths and hospitalizations due to falls is needed.

The alcohol-attributable death rate for homicide for blacks was more than five times that of whites (147 vs 26 deaths per 1,000,000 persons). These findings are consistent with an earlier study by Sutocky and colleagues [10] which also found a higher alcohol-attributable death rate for blacks for homicide during the 1980s in California. However, the current alcohol-attributable fraction for homicide is based upon the victim's blood alcohol content and does not include information pertaining to the perpetrator of the crime [14]. Therefore, it is unclear the proportion of crimes committed while the offender is under the influence of alcohol, which could result in underreporting of alcohol involvement in homicide. Alcohol-attributable hospitalizations for assaults were also significantly higher for blacks than for whites (183 vs 45 deaths per $1,000,000$ persons). 
Table 11. Rate of Alcohol-Attributable Illness and Injury Hospitalizations Per 1,000,000 Persons by Sex, Hispanic Ethnicity and Race for California, 2006

\begin{tabular}{|c|c|c|c|c|c|c|c|}
\hline \multirow{2}{*}{ Condition } & \multirow{2}{*}{ Total } & \multicolumn{2}{|c|}{ Sex } & \multirow{2}{*}{$\begin{array}{l}\text { Hispanic } \\
\text { Ethnicity }\end{array}$} & \multicolumn{3}{|c|}{ Race } \\
\hline & & Male & Female & & White & Black & Other* \\
\hline \multicolumn{8}{|l|}{ Neuro-psychiatric conditions } \\
\hline Alcohol abuse & 18.3 & 24.5 & $12.1^{\mathrm{a}}$ & $8.3^{\mathrm{b}}$ & 17.4 & 16.4 & $1.6^{\mathrm{c}}$ \\
\hline Alcohol dependence syndrome & 129.0 & 164.4 & $93.6^{\mathrm{a}}$ & $32.6^{\mathrm{b}}$ & 135.4 & $60.6^{\mathrm{c}}$ & $8.8^{\mathrm{c}}$ \\
\hline Alcoholic psychosis & 196.8 & 300.2 & $93.3^{\mathrm{a}}$ & $85.8^{\mathrm{b}}$ & 189.0 & $154.3^{\mathrm{c}}$ & $13.1^{\mathrm{c}}$ \\
\hline \multicolumn{8}{|l|}{ Cardiovascular diseases } \\
\hline Hypertension & 14.6 & 16.0 & $13.2^{\mathrm{a}}$ & $8.3^{\mathrm{b}}$ & 9.8 & $38.5^{\mathrm{c}}$ & 7.5 \\
\hline Stroke hemorrhagic & 14.9 & 25.0 & $4.8^{\mathrm{a}}$ & $6.3^{\mathrm{b}}$ & 12.1 & 13.1 & 9.8 \\
\hline Stroke ischemic & 53.2 & 79.5 & 26.9 & $17.7^{\mathrm{b}}$ & 49.4 & 49.1 & $22.3^{\mathrm{c}}$ \\
\hline \multicolumn{8}{|l|}{ Digestive diseases } \\
\hline Alcoholic liver disease & 202.3 & 300.5 & $104.0^{\mathrm{a}}$ & $188.0^{\mathrm{b}}$ & 181.1 & $140.8^{\mathrm{c}}$ & $34.5^{\mathrm{c}}$ \\
\hline Acute pancreatitis & 136.5 & 127.3 & $145.7^{\mathrm{a}}$ & $89.4^{\mathrm{b}}$ & 115.4 & $167.4^{\mathrm{c}}$ & $42.3^{\mathrm{c}}$ \\
\hline Alcoholic gastritis & 18.1 & 26.9 & $9.2^{\mathrm{a}}$ & $12.7^{\mathrm{b}}$ & 15.8 & $18.4^{\mathrm{c}}$ & $1.8^{\mathrm{c}}$ \\
\hline Chronic pancreatitis & 38.7 & 35.7 & $41.7^{\mathrm{a}}$ & $21.6^{\mathrm{b}}$ & 32.7 & $80.2^{\mathrm{c}}$ & $8.2^{\mathrm{c}}$ \\
\hline Gastroesophageal hemorrhage & 18.7 & 24.3 & $13.1^{\mathrm{a}}$ & $10.0^{\mathrm{b}}$ & 15.9 & $22.1^{\mathrm{c}}$ & $7.1^{\mathrm{c}}$ \\
\hline Liver cirrhosis unspecified & 44.9 & 43.2 & $46.6^{\mathrm{a}}$ & $36.4^{\mathrm{b}}$ & 38.5 & $27.0^{\mathrm{c}}$ & $23.3^{\mathrm{c}}$ \\
\hline \multicolumn{8}{|l|}{ Unintentional injury } \\
\hline Falls & 592.9 & 437.2 & $748.6^{\mathrm{a}}$ & $171.8^{\mathrm{b}}$ & 609.8 & $292.3^{\mathrm{c}}$ & $181.2^{\mathrm{c}}$ \\
\hline Poisoning & 63.0 & 55.1 & $70.9^{\mathrm{a}}$ & $21.0^{\mathrm{b}}$ & 58.6 & $83.1^{\mathrm{c}}$ & $16.1^{\mathrm{c}}$ \\
\hline Motor-vehicle traffic crashes & 143.2 & 176.7 & $109.6^{\mathrm{a}}$ & $91.9^{\mathrm{b}}$ & 112.6 & 116.3 & $29.6^{\mathrm{c}}$ \\
\hline \multicolumn{8}{|l|}{ Violence } \\
\hline Assault & 75.3 & 129.1 & $21.5^{\mathrm{a}}$ & $62.4^{\mathrm{b}}$ & 45.4 & $183.0^{c}$ & $7.8^{\mathrm{c}}$ \\
\hline Attempted Suicide & 74.2 & 60.3 & $88.1^{\mathrm{a}}$ & $31.2^{\mathrm{b}}$ & 68.9 & $56.9^{c}$ & $15.7^{\mathrm{c}}$ \\
\hline
\end{tabular}

"Includes Asian, Hawaiian, Pacific Islander, Alaskan Native, and American Indian.

${ }^{a}$ Statistically significant difference from males $(\mathrm{p}<0.05)$

${ }^{\mathrm{b}}$ Statistically significant difference from Non-Hispanics $(\mathrm{p}<0.05)$.

${ }^{\mathrm{c}}$ Statistically significant difference from whites $(\mathrm{p}<0.05)$.

\section{Limitations}

The findings in this report are subject to several limitations. First, the ARDI methodology tends to underestimate the number of alcohol-attributable deaths and, as a result, the estimates obtained for California for both fatal and nonfatal conditions could also be underestimated [1]. Second, ARDI is not designed to assess morbidity of alcohol use and the validity of using it to determine the proportion of hospitalizations that were alcohol-attributable are unknown. Third, self-report of alcohol use has been found to be underestimated in surveys [18]. In addition, the BRFSS has been shown to underestimate certain patterns of drinking compared to other national surveys [19]. This results in underestimates of patterns of alcohol use which results in lower estimates for the calculation of attributable fractions for certain conditions in ARDI, resulting in an underestimate of the true number of alcohol-attributable deaths. Finally, there is also potential bias with regards to the way race and ethnicity are recorded on death certificates.
Since each county in California collects information on race and ethnicity differently (i.e., some use hospital records, other use a spokesperson for the decedent), it is unknown the true racial and ethnic breakdowns for each group. Research has shown that there is severe underreporting on death certificates for certain racial and ethnic groups including American Indian and Alaskan Natives [20].

\section{CONCLUSION}

Excessive alcohol use is attributed to a variety of harms and it is critical to examine demographically which groups are most affected. This knowledge helps to better tailor prevention efforts accordingly. For example, research has shown that exposure to outdoor alcohol advertising is associated with problem drinking among African American women even after controlling for family history of alcohol problems and socioeconomic status [21]. Efforts can be focused to limit alcohol advertising in predominantly African American neighborhoods. These types of targeted prevention programs have the ability to greatly impact specific groups and reduce the harm and costs associated with excessive levels of alcohol use. 
Table 12. Total Number of Hospitalizations for Alcohol-Attributable Injuries Due to Exposure to Alcohol for Individuals Under Age 21 by Sex for California, 2006

\begin{tabular}{|c|c|c|c|}
\hline \multirow{2}{*}{ Condition } & \multirow{2}{*}{ Total } & \multicolumn{2}{|c|}{ Sex } \\
\hline & & Male & Female \\
\hline $\begin{array}{l}\text { Alcohol poisoning } \\
\text { Acute pancreatitis } \\
\text { Alcohol dependence syndrome } \\
\text { Alcoholic gastritis } \\
\text { Alcoholic liver disease } \\
\text { Alcoholic psychosis } \\
\text { Chronic pancreatitis } \\
\text { Epilepsy } \\
\text { Gastroesophageal hemorrhage }\end{array}$ & $\begin{array}{c}22 \\
41 \\
25 \\
3 \\
5 \\
23 \\
7 \\
6 \\
4\end{array}$ & $\begin{array}{c}12 \\
12 \\
17 \\
3 \\
4 \\
18 \\
2 \\
3 \\
3\end{array}$ & $\begin{array}{c}10 \\
29 \\
8 \\
0 \\
1 \\
5 \\
5 \\
3 \\
1\end{array}$ \\
\hline $\begin{array}{l}\text { Conditions during pregnancy or perinatal period } \\
\text { Low birth weight prematurity IUGR death } \\
\text { Spontaneous abortion }\end{array}$ & $\begin{array}{c}84 \\
4\end{array}$ & $\begin{array}{c}52 \\
-\end{array}$ & $\begin{array}{c}32 \\
4\end{array}$ \\
\hline $\begin{array}{l}\text { Unintentional injury } \\
\text { Aspiration/suffocation } \\
\text { Drowning/submersion } \\
\text { Falls } \\
\text { Fire/flame } \\
\text { Firearm } \\
\text { Hypothermia } \\
\text { Machinery and cut/pierce } \\
\text { Other transport } \\
\text { Poisoning }\end{array}$ & $\begin{array}{c}7 \\
4 \\
228 \\
9 \\
26 \\
2 \\
153 \\
105 \\
72\end{array}$ & $\begin{array}{c}3 \\
2 \\
158 \\
8 \\
23 \\
1 \\
120 \\
83 \\
34\end{array}$ & $\begin{array}{c}4 \\
2 \\
70 \\
1 \\
3 \\
1 \\
33 \\
23 \\
38\end{array}$ \\
\hline Motor-vehicle traffic crashes & 939 & 587 & 352 \\
\hline $\begin{array}{l}\text { Violence } \\
\text { Child maltreatment } \\
\text { Assault } \\
\text { Attempted suicide }\end{array}$ & $\begin{array}{c}99 \\
507 \\
384\end{array}$ & $\begin{array}{c}64 \\
452 \\
115\end{array}$ & $\begin{array}{c}35 \\
55 \\
269\end{array}$ \\
\hline Total & 2759 & 1776 & 984 \\
\hline
\end{tabular}

Table 13. Rate of Alcohol-Attributable Illness and Injury Deaths and Hospitalizations Per 1,000,000 Persons by Sex and Age Groups for California, 2006

\begin{tabular}{|c|c|c|c|c|c|c|c|c|c|c|c|c|c|c|c|}
\hline \multirow[t]{2}{*}{ Condition } & \multicolumn{5}{|c|}{ Males } & \multicolumn{5}{|c|}{ Females } & \multicolumn{5}{|c|}{ Total } \\
\hline & $\begin{array}{c}0- \\
19\end{array}$ & $\begin{array}{c}20- \\
34\end{array}$ & $\begin{array}{c}35- \\
49\end{array}$ & $\begin{array}{c}50- \\
64\end{array}$ & $65+$ & $\begin{array}{c}0- \\
19\end{array}$ & $\begin{array}{c}20- \\
34\end{array}$ & $\begin{array}{c}35- \\
49\end{array}$ & $\begin{array}{c}50- \\
64\end{array}$ & $65+$ & $\begin{array}{c}0- \\
19\end{array}$ & $\begin{array}{c}20- \\
34\end{array}$ & $\begin{array}{c}35- \\
49\end{array}$ & $\begin{array}{c}50- \\
64\end{array}$ & $65+$ \\
\hline \multicolumn{16}{|l|}{ Deaths } \\
\hline $\begin{array}{l}\text { Alcohol } \\
\text { dependence } \\
\text { syndrome } \\
\text { Motor-vehicle } \\
\text { traffic crashes } \\
\text { Homicide }\end{array}$ & $\begin{array}{c}0 \\
20.5 \\
36.6\end{array}$ & $\begin{array}{c}5.8 \\
125.1 \\
125.6\end{array}$ & $\begin{array}{l}33.6 \\
79.3 \\
49.1\end{array}$ & $\begin{array}{l}85.1 \\
59.4 \\
30.2\end{array}$ & $\begin{array}{l}39.4 \\
27.4 \\
11.3\end{array}$ & $\begin{array}{c}0 \\
7.8 \\
3.6\end{array}$ & $\begin{array}{c}1.3 \\
28.7 \\
14.6\end{array}$ & $\begin{array}{c}8.7 \\
21.5 \\
12.6\end{array}$ & $\begin{array}{l}17.9 \\
13.4 \\
10.9\end{array}$ & $\begin{array}{c}15.5 \\
10.6 \\
6.2\end{array}$ & $\begin{array}{c}0 \\
14.2 \\
77.5\end{array}$ & $\begin{array}{c}3.5 \\
76.9 \\
70.1\end{array}$ & $\begin{array}{l}21.2 \\
50.4 \\
30.8\end{array}$ & $\begin{array}{l}51.5 \\
36.6 \\
20.6\end{array}$ & $\begin{array}{c}25.7 \\
17.8 \\
8.4\end{array}$ \\
\hline \multicolumn{16}{|l|}{ Hospitalizations } \\
\hline $\begin{array}{l}\text { Alcoholic liver } \\
\text { disease } \\
\text { Alcohol } \\
\text { dependence } \\
\text { syndrome } \\
\text { Falls } \\
\text { Motor-vehicle } \\
\text { traffic crashes }\end{array}$ & $\begin{array}{c}0 \\
0 \\
23.7 \\
93.4\end{array}$ & $\begin{array}{c}54.1 \\
5.8 \\
128.3 \\
261.2\end{array}$ & $\begin{array}{c}492.3 \\
33.6 \\
234.9 \\
197.4\end{array}$ & $\begin{array}{c}897.7 \\
85.1 \\
515.8 \\
196.5\end{array}$ & $\begin{array}{c}401.3 \\
39.4 \\
2919 \\
187.8\end{array}$ & $\begin{array}{c}0 \\
0 \\
10.4 \\
57.3\end{array}$ & $\begin{array}{c}20.1 \\
1.3 \\
78.0 \\
145.2\end{array}$ & $\begin{array}{c}191.9 \\
8.7 \\
160.9 \\
101.7\end{array}$ & $\begin{array}{c}283.1 \\
17.9 \\
578.8 \\
119.2\end{array}$ & $\begin{array}{c}96.0 \\
15.5 \\
4853.2 \\
159.7\end{array}$ & $\begin{array}{c}0 \\
0 \\
17.1 \\
75.4\end{array}$ & $\begin{array}{c}37.1 \\
3.5 \\
103.2 \\
203.2\end{array}$ & $\begin{array}{c}342.1 \\
21.2 \\
197.9 \\
149.6\end{array}$ & $\begin{array}{c}590.4 \\
51.5 \\
547.4 \\
157.9\end{array}$ & $\begin{array}{c}226.0 \\
25.7 \\
4029 \\
171.7\end{array}$ \\
\hline
\end{tabular}

For all age groups, males and females have statistically significant differences in rates $(\mathrm{p}<.05)$. 


\section{REFERENCES}

[1] Centers for Disease Control and Prevention. Alcohol-attributable deaths and years of potential life lost --- United States, 2001. Morbid Mortal Wkly Rep 2004; 53(37): 866-70.

[2] Mokdad AH, Marks JS, Stroup DF, Gerberding JL. Actual causes of death in the United States, 2000. JAMA 2004; 29(10): 1238-45.

[3] Alcohol-Related Disease Impact (ARDI) software [database on the Internet] 2008. Available from: http//:www.cdc.gov/alcohol [Acceseed: February 2009].

[4] National Institute on Alcohol Abuse and Alcoholism. NIAAA council approves definition of binge drinking. Publication No. 045346. NIH 2004; Issue no. 3.

[5] United States Department of Agriculture and United States Department of Health and Human Services. Alcoholic Beverages. Chapter 9, US Government Printing Office 2005.

[6] Harwood H. Updating estimates of the economic costs of alcohol abuse in the united states: estimates, update methods, and data. Rockville, MD: National Institute of Drug Abuse and the National Institute on Alcohol Abuse and Alcoholism, National Institutes of Health, Department of Health and Human Services 2000.

[7] Rosen SM, Miller TR, Simon S. The cost of alcohol in California. Alcohol Clin Exp Res 2008; 32(11): 1925-36.

[8] Naimi T, Brewer R, Mokdad A, Denny C, Serdula M, Marks J. Binge drinking among US adults. JAMA 2003; 28(1): 70-5.

[9] Centers for Disease Control and Prevention. BRFSS Prevalence and Trends Data. Atlanta, GA; Available from: www.cdc.gov/brfss [Acceseed: February 2009].

[10] Sutocky JW, Shultz JM, Kizer KW. Alcohol-related mortality in California, 1980-1989. Am J Public Health 1993; 83(6): 817-23.

[11] Polednak AP. Secular trend in U.S. black-white disparities in selected alcohol-related cancer incidence rates. Alcohol Alcohol 2007; 41(4): 125-30.
[12] Behavioral Risk Factor Surveillance System Prevalence Data. 2006. Available from: http://apps.nccd.cdc.gov/brfss/ [Accessed February 2009].

[13] English DR, Holman CDJ, Milne E, et al. The quantification of drug caused morbidity and mortality in Australia. Canberra: Commonwealth Department of Human Services and Health 1995.

[14] Smith GS, Branas CC, Miller TR. Fatal nontraffic injuries involving alcohol: A metaanalysis. Ann Emerg Med 1999; 33(6): 659-68.

[15] National Highway Traffic Safety Administration (NHTSA). Fatality Analysis Reporting System (FARS) 2009; Available from: http://www.nhtsa.dot.gov/people/ncsa/fars.html

[16] Office of Management and Budget. Recommendations from the interagency committee for the review of the racial and ethnic standards to the office of management and budget concerning changes to the standards for the classification of federal data on race and ethnicity. Washington, DC 1997; pp. 36873-946.

[17] Miller TR, Spicer RS, Smith GS. Does Alcohol Cause Injury: The Bottle's Fingerprints on the Victims. 2003. (unpublished manuscript).

[18] Smith PF, Remington PL, Williamson DF, Anda RF. A comparison of alcohol sales data with survey data on self-reported alcohol use in 21 states. Am J Public Health 1990; 80: 309-12.

[19] Miller JW, Gfroerer JC, Naimi TS, Mokdad A, Giles WH. Prevalence of adult binge dirnking: A comparison of two national surveys. Am J Prev Med 2004; 27(3): 197-204.

[20] Arias E, Schauman WS, Eschbach K, Sorlie PD, Backlund E. The validity of race and Hispanic origin reporting on death certificates in the United States. Vital Health Stat 2008; 148: 1-23.

[21] Kwate NOA, Meyer IH. Association between residential exposure to outdoor alcohol advertising and problem drinking among African American women in New York City. Am J Public Health 2009; 99(2): 228-30.

(C) Mandy Stahre; Licensee Bentham Open.

This is an open access article licensed under the terms of the Creative Commons Attribution Non-Commercial License (http://creativecommons.org/licenses/by$\mathrm{nc} / 3.0 /$ ) which permits unrestricted, non-commercial use, distribution and reproduction in any medium, provided the work is properly cited. 